\title{
Psychosocial Work Quality, Work-Family Conflict, and Psychological Distress: \\ A Comparison of Single and Partnered Mothers
}

\author{
A Thesis Submitted to the College of Graduate Studies and Research \\ in Partial Fulfillment of the Requirements for the \\ Degree of Master of Science in the \\ Department of Community Health \& Epidemiology \\ University of Saskatchewan \\ Saskatoon, Saskatchewan
}

by

Ewelina Dziak

${ }^{\circ}$ Copyright Ewelina Dziak, August 2008. All rights reserved. 


\section{PERMISSION TO USE}

In presenting this thesis in partial fulfillment of the requirements for a Postgraduate degree from the University of Saskatchewan, I agree that the Libraries of this University may make it freely available for inspection. I further agree that permission for copying of this thesis in any matter, in whole or in part, for scholarly purposes may be granted by the professor who supervised my thesis work or, in her absence, by the Head of the Department or the Dean of the College in which my thesis work was done. It is understood that any copying or publication or used of this thesis or parts thereof for financial gain shall not be allowed without my written permission. It is also understood that due recognition shall be given to me and the University of Saskatchewan in any scholarly use which may be made of any material in my thesis.

Requests for permission to copy or make other use of material in this thesis in whole or in part should be addressed to:

Head of the Department of Community Health and Epidemiology

College of Medicine

University of Saskatchewan

Saskatoon, Saskatchewan

S7N 5E5 


\begin{abstract}
Research suggests that single mothers experience poorer mental and physical health than their partnered counterparts. This health differential has been attributed, in large part, to the chronic economic and social stressors to which many single mothers are exposed. Less research, however, has focused on the well-being of single mothers who are employed, despite their growing presence in the Canadian labour force. Using data from a telephone survey of employed parents in a mid-sized Western Canadian city conducted in 2005, the aim of this study was to: (1) compare the mental health of employed, single mothers relative to partnered mothers; and (2) explore the potential role of work-family conflict and psychosocial job characteristics as explanations for any observed differences in psychological distress. Analyses were restricted to 674 employed mothers (438 partnered and 236 single), who were $25-50$ years old, with at least one child in the household under the age of 20 years. Bivariate analysis indicated that compared to partnered mothers, employed single mothers reported significantly higher levels of psychological distress, work-to-family conflict and family-to-work conflict. Single mothers were also more likely to be employed in a high-strain psychosocial work environment (i.e., high demand and low control). Multiple linear regression revealed that after adjusting for key sociodemographic characteristics, psychosocial work quality and work-family conflict, single parenthood was no longer statistically significantly associated with psychological distress. These findings suggest that being a single mother in and of itself need not result in poorer mental health, but greater attention needs to be paid to the economic and psychosocial work environment of single mothers, including policies to facilitate work-family balance.
\end{abstract}




\section{ACKNOWLEDGMENTS}

I would like to acknowledge and extend my sincere appreciation to several people whose contributions and support made this thesis possible:

First and foremost, deepest gratitude is given to my supervisor and mentor

Dr. Bonnie Janzen; over the past year you have offered me so much more than research training. Without your direction, guidance, and overall patience, from the beginning to the very end, this thesis would not have been possible -thank you.

To my committee members: Dr. Kathryn Green, for your insightful comments; and Dr. Nazeem Muhajarine for chairing my committee.

To my friends and family: without your love, support and encouragement over the years, I surely would not have survived this challenging chapter in my life. 


\section{TABLE OF CONTENTS}

PERMISSION TO USE...................................................................................................... i

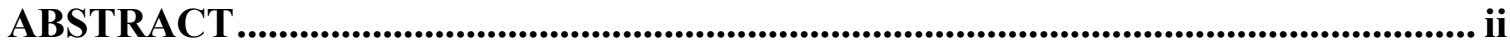

ACKNOWLEDGMENTS .............................................................................................. iii

TABLE OF CONTENTS .................................................................................................. iv

LIST OF TABLES

LIST OF FIGURES ..................................................................................................... vii

TERMS USED IN THIS THESIS ...................................................................... viii

\section{CHAPTER 1: INTRODUCTION}

1.1 Background ........................................................................................................................1

1.2 Purpose and Research Questions ..............................................................................2

CHAPTER 2: LITERATURE REVIEW

2.1 Sociodemographic Overview.............................................................................................

2.2 The Mental Health of Single Mothers ...............................................................................7

2.3 Employment, Single Mothers, and Mental Health ..........................................................7

2.3.1 Psychosocial Work Quality and Mental Health ..................................................9

2.3.2 Work-Family Conflict and Mental Health ...........................................................11

2.4 Summary.............................................................................................................................13

\section{CHAPTER 3: METHODOLOGY}

3.1 Participants...................................................................................................................15

3.2 Measures ..................................................................................................................16

3.2.1 Dependent Variable ...............................................................................................16

3.2.2 Independent Variables............................................................................................16

3.2.3 Covariates ................................................................................................................18

3.3 Analyses .........................................................................................................................19 


\section{CHAPTER 4: RESULTS}

4.1 Characteristics of the Study Sample ...................................................................21

4.2 Correlates of Psychological Distress............................................................25

\section{CHAPTER 5: DISCUSSION}

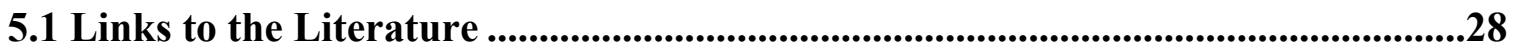

5.2 Study Limitations...............................................................................................33

5.3 Study Implications .....................................................................................................34

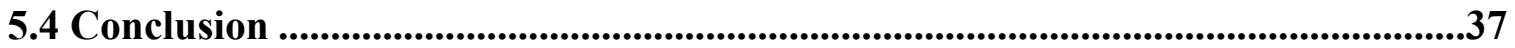

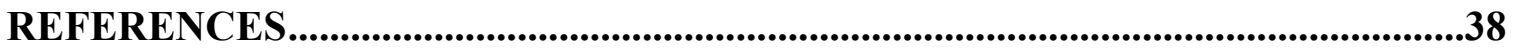

APPENDIX A: VARIABLES USED IN ANALYSIS ........................................44

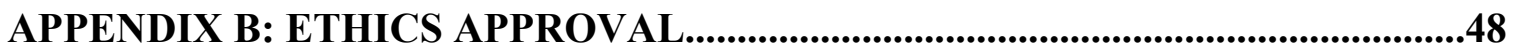




\section{LIST OF TABLES}

Table 1: Sociodemographic Profile of 25-54 year old Partnered Mothers and Single Mothers over Time, Canada

Table 2: Pearson Correlations among Psychosocial Job Quality, Work-family Conflict and Psychological Distress

Table 3: Ranges and Internal Reliability Estimates for Study Scales.

Table 4: Demographic, Psychosocial, and Work-Family Conflict Characteristics, by Partner Status

Table 5: Summary of Hierarchical Linear Multiple Regression Predicting

Psychological Distress 


\section{LIST OF FIGURES}

Figure 1: Demand-Control Model of Job Strain.......................................................19 


\section{TERMS USE IN THIS THESIS}

Family-to-work conflict - When family demands interfere with work responsibilities.

Partnered mother - A woman who is married/living with a partner and has at least one child under the age of 20 years in the household.

Psychosocial work quality - Psychological (e.g. decision latitude) and social aspects (e.g. co-worker social support) of the work environment which may impact health.

Single/lone mother - A woman who is separated/divorced, widowed, or never married and has at least one child under the age of 20 years in the household.

Strain-based family-to-work conflict - When concerns and anxieties associated with family responsibilities interfere with meeting work demands.

Strain-based work-to-family conflict - When concerns and anxieties associated with work interfere with meeting family responsibilities.

Time-based family-to-work conflict - When time committed to family activities reduces available time for work.

Time-based work-to-family conflict - When time committed to work reduces available time to participate in family activities.

Work-family conflict - A type of inter-role conflict occurring from incompatible role pressures from the work and family domains.

Work-to-family conflict - When work demands interfere with family responsibilities. 


\section{CHAPTER 1}

\section{INTRODUCTION}

\subsection{Background}

Decreasing marriage rates and increasing divorce rates in North America over the last three decades have resulted in substantial growth in the number of single parent families.(1) In Canada in 2006, single parent families accounted for $15.9 \%$ of all families, up from 11\% in 1981.(2) Single parent families are overwhelmingly led by women, comprising $80.1 \%$ of all such families in 2006 . A large body of research reveals that single mothers experience poorer mental and physical health than their partnered counterparts.(3-6) This health differential has been attributed, in large part, to the chronic economic and social stressors to which many single mothers are exposed.(4, 7$)$ Less research has focused on the well-being of single mothers who are employed, despite their growing presence in the Canadian labour force. In 2004, just over two thirds of single mothers were employed, compared with less than half in 1976.(1)

One might expect less of a health differential between employed single and married mothers, given the large body of evidence pointing to the health enhancing impact of employment for women.(8-10) At the same time, however, some research suggests that employed single mothers are more likely to be working in positions of lower pay and status than partnered women, making them less likely to reap the financial benefits of paid work. $(4,5,11)$ Lower paying jobs also tend to be associated with particular psychosocial job characteristics (e.g., less job variety, higher psychological work load) which in turn may lead to an increased risk of poor health.(12-15) To date, however, most research on employed single mothers has focused on employment status 
per se, rather than on the psychosocial quality of paid work and the potential role it may play in explaining observed mental health differences between partnered and single mothers.

Employed single mothers may also experience greater challenges than partnered women in simultaneously negotiating family responsibilities and workplace demands.(16, 17) Conflict between work and family life has been associated with a number of negative physical and mental health outcomes in the research literature. $(18,19)$ However, workfamily research has predominantly drawn on the experiences of those in dual-earner households, while studies involving the efforts of single mothers to negotiate workfamily balance, and the potential impact of that struggle on their well-being, have been sparse.(20) Although a very limited amount of research suggests that employed single mothers may experience higher levels of work-family conflict than partnered mothers, $(16,17)$ more research is clearly needed, particularly in relation to mental health outcomes. In addition, work-family conflict is a complex phenomena, with the most recent conceptualizations emphasizing different forms (e.g., time-based versus strainbased) and different directions (work-to-family and family-to-work).(21) It is possible that single and partnered mothers may differ on some but not all aspects of work-family conflict, which would have implications for informing specific policies designed to enhance work-life balance.

\subsection{Purpose and Research Questions}

Using data from a recently conducted survey of employed parents in a mid-sized Western Canadian city, the aim of this study was to compare the mental health of employed single mothers relative to partnered mothers and to explore the potential role of 
work-family conflict and psychosocial job characteristics as explanations for any observed differences in mental health. More specifically, the following research questions were addressed:

1. Do employed single mothers experience more psychological distress than employed partnered mothers?

2. Are employed single mothers exposed to poorer psychosocial work environments than partnered mothers?

3. Do employed single mothers experience more work-family conflict than partnered mothers?

4. If single mothers do experience more psychological distress than partnered mothers, to what extent can this be explained by differences between these two groups in their experience of work-family conflict and/or in the psychosocial quality of their work environment? 


\section{CHAPTER 2}

\section{LITERATURE REVIEW}

This chapter begins with a sociodemographic overview of single and partnered mothers in Canada, followed by a review of the pertinent research concerning the relationship between single parenting, employment, psychological well-being, psychosocial work quality and work-family conflict.

\subsection{Sociodemographic Overview}

The proportion of Canadian families headed by women has increased substantially over the last several decades, from one in ten in 1971 to one in five in 2001.(1) In 2006, there were over one million female-headed lone parent families in Canada. In addition to comprising a larger share of Canadian families over time, the sociodemographic profile of single mothers in Canada has changed.(2) Compared with 1981, single mothers in 2001 were older and had fewer children living in the household (Table 1). Although the largest single category of female single mothers is "divorced/ separated" (49\% in 2001), this proportion is down from 54\% in 1986 . Conversely, the proportion of single mothers who have never been married has increased, comprising $29 \%$ of all single mothers in 2001 , compared to $15 \%$ in 1986 .(1) The educational attainment of single mothers has also shown considerable change over the last two decades, with more than double the percentage graduating from high school in 2001 than in 1981, and almost triple the percentage receiving a bachelor degree (see Table 1).(2) Tied with higher educational levels is a dramatic increase in the proportion of single mothers with jobs, from $58.7 \%$ in 1981 to $71 \%$ in 2001 . The increasing share of employed single mothers, coupled with higher levels of educational attainment, are in 
Table 1: Sociodemographic Profile of 25-54 year old Partnered Mothers and Single Mothers over Time, Canada

\begin{tabular}{|c|c|c|c|}
\hline & \multicolumn{2}{|c|}{$\begin{array}{c}\text { Single } \\
\text { Mothers }\end{array}$} & \multirow{2}{*}{$\begin{array}{c}\begin{array}{c}\text { Partnered } \\
\text { Mothers }\end{array} \\
2001 \\
\end{array}$} \\
\hline & 1981 & 2001 & \\
\hline Mean age (years) & 37.8 & 38.7 & 38.7 \\
\hline Average number of children & 1.80 & 1.70 & 1.90 \\
\hline
\end{tabular}

Education

Less than high school

$\begin{array}{lll}45.8 & 21.9 \quad 16.6\end{array}$

High school diploma

$1.90 \quad 14.2 \quad 17.2$

At least some postsecondary

$\begin{array}{lll}48.2 & 52.3 \quad 46.8\end{array}$

Bachelor's degree or higher

$4.10 \quad 11.6 \quad 19.4$

Employed

Overall employed

$\begin{array}{lll}58.7 & 71.1 & 75.0\end{array}$

Mostly full-time

$\begin{array}{lll}50.8 & 60.8 & 58.0\end{array}$

Mostly part-time

$\begin{array}{lll}15.2 & 17.1 & 23.8\end{array}$

Did not work

$\begin{array}{lll}34.0 & 22.1 & 18.2\end{array}$

Mostly full-time, full-year

\begin{tabular}{lll}
32.1 & 40.3 & 40.2 \\
\hline $\mathbf{1 9 8 0}$ & $\mathbf{2 0 0 0}$ & $\mathbf{2 0 0 0}$
\end{tabular}

Economic

Employment earnings (dollars)

$14,700 \quad 19,900 \quad 22,700$

Low-income rate (\%)

$\begin{array}{lll}51.8 & 43.0 & 8.0\end{array}$

Source: adapted from (2) 
turn partially responsible for a decreasing low income rate, from $52 \%$ in 1980 to $43 \%$ in 2000. Steady, full-time employment appears especially critical for the financial wellbeing of single mothers: $14 \%$ of full-time employed single mothers working year round had a low income in 2003 , compared with $62 \%$ of mothers in "other" employment categories.(2)

Despite such gains, however, it is important to recognize that single mothers in Canada continue to be at a significant socioeconomic disadvantage when compared with their partnered counterparts. As shown in Table 1, a higher proportion of partnered than single mothers in 2001 had a university degree. Even though a decrease in the low income rate is observed among single mothers over time, single mothers were still more than five times as likely to experience low income as partnered mothers in 2001. It is also important to keep in mind that single mothers are a heterogeneous group and some of the positive socioeconomic trends observed over time may not apply to all subgroups of single mothers. For example, although employment figures appear similar for partnered and single mothers, the age of the youngest child has a much stronger impact on the employment status of single mothers: among women with a child under the age of 3 in $2004,67 \%$ of those with a spouse and $46 \%$ of female lone parents were employed.(1) Similarly, the gains in educational attainment, employment, and income levels were considerably less marked for younger single mothers (25-34 years of age) compared with older single mothers. Younger single mothers are also more likely than their older counterparts to work part-time, occupy lower skilled and lower paying jobs, and to live in a low income household. (2) 


\subsection{The Mental Health of Single Mothers}

Research conducted in the United States, Australia, and Europe has consistently shown that single mothers experience poorer mental and physical health than mothers in two-parent households.(6, 22-26) In Canada, researchers have focused primarily on the mental health correlates of family structure and have similarly reported that single mothers, compared to partnered mothers, have elevated levels of psychological distress,(5, 27) unhappiness,(5) alcohol consumption,(28) mental health service utilization,(29) and nearly double the prevalence of major depression. $(4,29)$ Investigations exploring the reasons underlying these differences in mental health status have adopted, for the most part, a role stress perspective, focusing on the chronic social and economic disadvantages that many single mothers must cope with.(27) Indeed, many studies have shown single motherhood to be associated with greater exposure to a number of stressful life conditions known to increase the risk of poor mental health, such as economic hardship, $(7,22,23)$ physical and sexual violence, $(25,30)$ a lack of social support, $(4,23)$ and higher levels of chronic stress and adverse life events.(4) Although statistically adjusting for these chronic strains, financial hardship in particular, has been found to minimize mental health differences between single and partnered mothers, an excess of psychological ill-health among single mothers generally remains. $(4,7,31)$

\subsection{Employment, Single Mothers, and Mental Health}

Because of the increase in labour force participation of women with dependent children over the last three decades in Canada and elsewhere,(1) whether the combination of being an employee and a mother is good or bad for women's health, be they single or partnered, has become an increasingly important policy issue. Several contrasting views 
have emerged in the research literature concerning the association between multiple role occupancy and well-being, each predicting different outcomes. The role overload hypothesis focuses on the premise that human energy is limited. The more roles a person occupies, the more strain is experienced, and the greater the likelihood of negative effects on health and well-being.(32) In contrast, the role enhancement model highlights the potential economic, social, and psychological benefits of occupying parent and paid worker roles, and proposes health enrichment as a result of simultaneous participation in these roles.(33) Interestingly, although experience and common sense strongly suggests that role overload is experienced by many employed mothers, empirical research indicates that, on average, women who occupy more roles experience better physical and psychological well-being than those who have fewer roles - at least for married women.(33-35)

But what about single mothers? One principle underlying "welfare-to-work" programs in many countries is the notion that employment can provide a vehicle out of poverty for socially and economically disadvantaged groups, such as single mothers, ultimately leading to improved physical, mental, and social well-being.(3) However, whether employment actually serves to enhance the mental health of single mothers, or detract from it, is currently unclear in the research literature. $(3,27)$ Some research suggests that employment may have a positive impact, to varying degrees, on the health of single mothers. For example, in a British study, Whitehead and colleagues found that between $42 \%$ and $58 \%$ of the excess poor health of lone mothers compared to partnered mothers could be accounted for by the joint effects of poverty and joblessness.(36) In Canada, researchers analyzing cross-sectional data from Statistics Canada's National 
Population Health Survey from 1994-1995 and 1998-1999 reported unemployed, single mothers to be twice as likely as women in other employment/family structure groups to report high levels of psychological distress. In the same study, no statistically significant difference in distress was found between employed single mothers and employed married mothers, leading the authors to recommend that "employment strategies that consider the special needs of lone mothers should be developed" (37; p. 7). Other research has similarly reported that adjusting for employment (and often other socioeconomic indicators simultaneously) attenuates some of the health differential between partnered and single mothers. $(6,7,36,37)$ However, in contrast to these findings, a detrimental impact of employment on the mental health of single mothers has also been documented. $(29,38)$ In a longitudinal study of mothers moving in and out of employment in Ontario,(38) no reduction in psychological distress was observed among single mothers who made the transition from unemployment into paid work. For partnered mothers, however, employment led to a statistically significant reduction in psychological distress, after adjusting for caregiver strains. Other research has also linked employment status with poorer mental health among single mothers, especially full-time employment.(22, 30, 39)

\subsubsection{Psychosocial Work Quality and Mental Health}

A major limitation of the research examining the role of employment in the relationship between family structure and mental health among women is the lack of explicit attention to the psychosocial quality of paid work. As previously indicated, although similar proportions of Canadian single mothers and partnered mothers are employed, single mothers are, on average, more likely to occupy lower-paying and lower 
status jobs that do not offer the same financial and psychosocial rewards enjoyed by their partnered counterparts. $(2,5)$ Lower paying jobs tend to be characterized by fewer chances to learn and develop skills, higher psychological work load, and less job variety - characteristics which in turn have been associated with a greater risk of ill health.(1215) A number of conceptual models have been developed which highlight the importance of the psychosocial work environment in the health of employed adults, the most common being Robert Karasek's Job Strain Model.(12) Within this framework, workers' job demands (e.g., pace, effort, volume) interact with their level of decision latitude (e.g. decision authority, opportunity to use skills) to determine the psychosocial quality of their work. The most damaging reactions (e.g., fatigue, anxiety, depression) occur when the psychological demands of the job are high and the worker's decision latitude is low.(40) Although the early focus of this research was on men, understanding the qualities and characteristics of paid work which impact women's health has increased greatly over the last two decades. $(13,41)$ Numerous studies have reported significant associations between high levels of psychosocial demands on the job and poor physical and mental health outcomes. $(14,41)$ Resources in the work environment have been recognized as playing an important role in offsetting the potential harmful effects of a highly demanding job. A sense of control over work activities has been identified as particularly critical for promoting health and well-being. $(40,42,43)$

The importance of considering work quality in the relationship between single motherhood status and mental health was suggested in a recent study of long-term, single mothers in Sweden.(26) Consistent with other research, this study found lone mothers to be at increased risk of numerous physical and mental health outcomes compared to 
married mothers. However, when stratified by job type, lone parenthood was only associated with higher rates of suicide, accidents or addiction among women in manual job, not those in high-or-medium grade, non-manual jobs. Additional research is clearly needed to document differences in the psychosocial paid work environment of single and partnered mothers and to what extent such differences may assist in explaining disparities in mental health.

\subsubsection{Work-Family Conflict and Mental Health}

Another potential factor which may explain the conflicting findings regarding single motherhood, employment and mental health is a lack of comparability between single and partnered mothers in access to the resources needed to cope with the dual demands of work and family life. Work-family conflict is most often defined as "a type of inter-role conflict that occurs as a result of incompatible role pressures from the work and family domains."(44; p.77 ) Perceived conflict between work and family life has been associated with a number of negative physical and mental health outcomes in the research literature, including psychological distress, depression and anxiety.(19, 45-47)

However, work-family research has mostly drawn on the experiences of women in dual-earner households.(48-50) Studies involving single parents' effort to negotiate work-family balance have been sparse. Nonetheless, the numerous barriers and challenges that single employed mothers are forced to overcome give reason to believe that this group of women may be more susceptible to work-family conflict than those in dual-earner contexts. In addition to having increased role demands, single mothers tend to have more limited resources at their disposal, a greater urgency for paid employment, and stronger constraints regarding job mobility.(51-53) Single mothers generally report less 
perceived social support than partnered mothers,(4) adding to the differences between these two groups of women that could account for poorer health. A partner can be a primary source of instrumental and emotional support for a mother. It is also likely that parental demands limit the amount of time and availability single mothers have to participate in various social events, as well as time necessary to connect with friends. Several earlier studies examining the differences between single and partnered mothers found that single mothers see themselves as having less support, less personal time, more stress, and greater difficulty balancing work and home life. $(51,54)$

Several recent studies have examined work-family conflict in relation to single mothers, but with notable limitations. Ciabattari,(55) while importantly highlighting some of the consequences of work-family conflict for low-income, unmarried mothers (i.e., lower employment rates and increased employment instability), did not include a comparison group of partnered mothers or mental health outcomes. Avison and colleagues recently examined the relationship between family structure, stress and psychological distress in a longitudinal sample of Canadian women.(27) One of the key stressors considered in this study was work-family conflict. Although the authors found single mothers to experience significantly higher levels of work-family conflict than partnered mothers (at the first measurement period), work-family conflict was not an important predictor of family structure differences in psychological distress.

A major limitation of the Avison study, however, was their measure of workfamily conflict which was developed specifically for their study and assessed only a single dimension of work-family conflict. Work-family conflict is a complex phenomenon and current conceptualizations emphasize the bidirectional nature of work- 
family conflict, in that family demands can interfere with work responsibilities, (familyto-work conflict) and work demands can interfere with family responsibilities, (work-tofamily conflict).(18, 19,21) In addition, different forms of work-family conflict have been described in the literature, the most common being time-based and strain-based conflict.(56) Time-based conflict arises when time committed to one sphere, e.g. family, reduces available time to participate in the other sphere, e.g. work.(21) Strain-based conflict occurs when concerns and anxieties associated with one sphere interferes with meeting the demands of the other sphere. The lack of significant findings by Avison et al. may be due to their use of a study-specific scale (possessing unknown psychometric properties) which fails to indicate the direction and type of work-family conflict. That is, some aspects of work-family conflict may be more germane than others to understanding mental health inequalities between partnered and single employed mothers.

\subsection{Summary}

Although considerable research has documented the poorer mental and physical health of single mothers compared to partnered mothers, very little research has focused on the well being of employed single mothers, despite their growing presence in the Canadian labour force. Of the research which has considered employment, the focus has been on employment status per se rather than on the psychosocial quality of paid work and the potential role it may play in explaining observed mental health differences between the two groups of women. Research examining potential differences between single and partnered mothers in work-family conflict is also rare, particularly in relation to mental health outcomes and using psychometrically sound measures of work-family conflict. To address these gaps, the aim of this study was to compare the mental health of 
employed, single mothers relative to partnered mothers and to explore the potential role of different types of work-family conflict and workplace psychosocial quality as explanations for any observed differences in psychological distress. 


\section{ChAPTER 3}

\section{METHODOLOGY}

Data for the present study were obtained from a gender, work, family and health telephone survey conducted during the winter of 2004/2005 in a mid-sized city (population of approximately 200,000) in western Canada. Provided in the sections which follow are the details concerning the sampling strategy, study participants, the dependent and independent variables, and the analysis plan.

\subsection{Participants}

The sampling frame for the gender, work, family and health study included all registered phone numbers within city limits. Interviewers randomly dialed the phone numbers; in households with more than one eligible person, one was randomly selected to be interviewed. Telephone interviews averaged 40 minutes in length and were conducted using a computer-assisted telephone interviewing system. Sample eligibility was limited to those who were: 1) English-speaking, 2) between the ages of 25 and 50 years, 3) employed full-time or part-time, and 4) the parent of at least one child under the age of 20 years. The goal was to sample a broad cross-section of employed parents in terms of economic circumstances, marital status, and job type. Toward this end, approximately equal proportions of participants were selected in terms of gender, age group (25-34 yrs; 35-54 yrs), and educational attainment (high school or less; some post-secondary; university/college degree). Although a total of 1160 people participated, for the present study, analyses were restricted to 674 employed mothers (438 partnered and 236 single). 


\subsection{Measures}

The dependent variable was psychological distress. The independent variables were partner status, psychosocial work quality, work-family conflict, and various sociodemographic characteristics. Please refer to Appendix A for a detailed list of all the variables. The operationalization of these constructs are described below.

\subsubsection{Dependent Variable}

The Kessler-6 measure was used to assess non-specific psychological distress. The 6-item self-report questionnaire was designed to measure symptoms of behavioural, emotional, cognitive, and psychophysiological manifestations of psychological distress.(57) The Kessler-6 has been shown to be a sensitive screen for DSM-IV disorders in general population samples. $(58,59)$ Using Kessler et al.'s original 5-point response scale $(0=$ none of the time to $4=$ all of the time $)$, respondents were asked to estimate how often in the past 30 days they had experienced six symptoms of psychological distress. Sample items include "How often in the past 30 days did you feel so depressed that nothing could cheer you up?", “How often did you feel hopeless?", and "How often did you feel restless or fidgety?" Each respondent's scores were totaled across all the items, with higher scores indicating higher levels of psychological distress.

\subsubsection{Independent Variables}

Partner status was a dichotomous variable based on reported current marital status. Partnered women were those who indicated that they were married or living with a partner. Unpartnered women were those who were separated, divorced, widowed, or never married. The various categories of unpartnered status were collapsed into a single group based on analyses indicating the absence of any statistically significant differences 
between groups on psychological distress, psychosocial work quality, or work-family conflict.

Work-Family Conflict was assessed by a 12-item, self-report scale developed by Carlson et al., in which respondents were asked to indicate, on a 5-point Likert type scale ( $1=$ strongly disagree to $5=$ strongly agree), the extent of agreement with various statements related to work-family conflict.(21) Participants' responses to questionnaire items were summed to form four subscales (with three items each) which focus on different types and directions of work-family conflict: 1) Time-Based Work-to-Family Conflict (e.g., "My work keeps me from my family activities more than I would like"); 2) Time-Based Family-to-Work Conflict (e.g., "The time I spend on family responsibilities often interfere with my work responsibilities"); 3) Strain-Based Work-to-Family Conflict (e.g., "When I get home from work I am often too frazzled to participate in family activities"), and 4) Strain-Based Family-to-Work Conflict (e.g., "Tension and anxiety from my family life often weakens my ability to do my job"). Higher scores reflect greater perceived work-family conflict. Evidence of the scales' discriminant validity and internal consistency has been reported in previous research. $(21,56)$

Psychosocial job quality was measured using the Job Content Questionnaire (JCQ), developed by Karasek and colleagues. (40) Items on the questionnaire combine to form several subscales reflecting key aspects of job quality. Decision latitude (9 items) consists of two dimensions: 1) decision authority (i.e., authority to make decisions concerning work); and 2) skill discretion (i.e., ability to use one's skills in doing work). Psychological demands (10 items) refer to "how hard workers work" (e.g., pace, effort, and volume of work) and the presence of conflicting demands. The questionnaire items 
were coded from 1 (strongly agree) to 4 (strongly disagree) according to the degree to which respondents agreed with each statement. All items were recoded in the same direction, and scores for each scale were calculated by summing the item scores. A higher score for each scale indicates greater job demands and decision latitude. To better represent Karasek's proposed model of job strain,(60) participants' scores on the psychological demands and decision latitude scales were then categorized using median splits, resulting in four dimensions of psychosocial work quality: high strain, low strain, active, and passive (see Figure 1). The negative health effects of work are a consequence of situations in which control over one's work is low and the demands of the job are high (i.e., high-strain work). The validity of the JCQ has been examined in a number of international studies.(40) In particular, predictive validity has been established in numerous studies of heart disease, psychological strain, depression, and musculoskeletal disorders. Confirmatory factor analyses conducted in the United States and Canada generally reveal factor patterns consistent with each the JCQ scales.

\subsubsection{Covariates}

Several additional variables were included in the analysis as potential confounders. Four of the covariates - age, number of children, weekly work hours, and perceived income adequacy - were treated as continuous variables. Perceived income adequacy was assessed with a single statement ("We have enough money to cover basic needs for food, housing and clothing") with which participants were asked to indicate their agreement on a scale from one (strongly disagree) to five (strongly agree). Higher scores indicated greater perceived income adequacy. Educational attainment (high school graduate or less, some post-secondary training, or college/university graduate) and the 
presence of at least one child under the age of five years in the household (yes/no) were treated as categorical variables.

Figure 1: Demand-Control Model of Job Strain

Job Control

\begin{tabular}{c|c|c|}
\multicolumn{1}{c}{} & \multicolumn{2}{c}{ Job Demands } \\
\multicolumn{1}{c}{ Low } & High \\
\cline { 2 - 3 } High & Low Strain & Active \\
\cline { 2 - 3 } Low & Passive & High Strain \\
\cline { 2 - 3 } & &
\end{tabular}

\subsection{Analyses}

Four research questions guided the present analysis: 1) Do employed single mothers experience more psychological distress than employed partnered mothers? 2) Are employed single mothers exposed to poorer psychosocial work environments than partnered mothers? 3) Do employed single mothers experience more work-family conflict than partnered mothers? 4) If single mothers do experience more psychological distress than partnered mothers, to what extent can this be explained by differences between these two groups in their experience of work-family conflict and/or in the psychosocial quality of their work environment?

Data analyses involved a multi-stage process consisting of univariate, bivariate, and multivariable analyses using SPSS 15.0 for Windows. Preliminary data analysis included examining statistical assumptions, assessing the reliability (i.e., internal 
consistency) of study scales, and conducting Pearson product correlations among the continuous variables. Descriptive analyses were undertaken for all of the variables, with frequencies and percentages determined for categorical variables, and means and standard deviations assessed for continuous variables. Bivariate analyses were conducted to examine the demographic, social, and mental health characteristics of the study participants according to partner status. Differences between single and partnered mothers were tested using chi-square tests for categorical variables and t-tests for continuous measures.

Multiple linear regression was used to examine the relationship between partner status and psychological distress. The first model assessed the crude association between partner status and distress, with subsequent models adjusting for potential confounding influences: Model 1: partner status; Model 2: age, educational attainment, perceived income adequacy, number of children, the presence of young children in the household, and weekly work hours; Model 3: psychosocial work quality (high strain, low strain, active and passive); and Model 4: work-family conflict (i.e., time-based work-to-family conflict, time-based family-to-work conflict, strain-based work-to-family conflict, and strain-based family-to-work conflict). At each stage of the analysis, particular attention was paid to any change in the primary relationship of interest (i.e., partner status and psychological distress) as sociodemographic characteristics, psychosocial work quality variables, and work-family conflict variables were added to the regression equation. 


\section{CHAPTER 4}

\section{ReSUlTS}

Intercorrelations between the continuous study variables are shown in Table 2 . The correlations among the variables were generally low. The work-family conflict variables were moderately correlated (.40 to .59$)$ although not at a level approaching collinearity.(61) The possible range of scores for each of the study scales, along with Cronbach's alpha, are shown in Table 3. With the exception of psychological demands ( $\alpha$ $=.64)$, all reported reliabilities are within an acceptable range.(62)

\subsection{Characteristics of the Study Sample}

Sociodemographic characteristics, psychosocial work quality, and work-family conflict measures, according to partner status, are shown in Table 4. Compared to single mothers, partnered mothers were older, reported fewer hours of paid work each week, and were more likely to perceive an adequate household income to cover basic needs. A significantly higher proportion of partnered mothers than single mothers reported having a college or university degree. Regarding psychosocial work quality, although no differences by partner status emerged in terms of job demands, single mothers reported significantly lower levels of decision latitude than partnered mothers and a significantly higher percentage of single mothers were categorized as being in the high strain quadrant (i.e., high job demands and low decision latitude) according to Karasek's model. Compared with single mothers, partnered mothers scored significantly lower on three of the four measures of work-family conflict: time-based work-to-family conflict, strainbased work-to-family conflict, and strain-based family-to-work conflict. Finally, single 
mothers reported significantly higher levels of psychological distress than partnered mothers.

Table 2: Pearson Correlations among Psychosocial Job Quality, Work-family Conflict and Psychological Distress

\begin{tabular}{|c|c|c|c|c|c|c|}
\hline & $\begin{array}{l}\text { Decision } \\
\text { latitude }\end{array}$ & $\begin{array}{c}\mathrm{W} \rightarrow \mathrm{F} \\
\text { (time- }^{\text {based) }}{ }^{\mathrm{a}}\end{array}$ & $\begin{array}{l}\mathbf{W} \rightarrow \mathbf{F} \\
\text { (strain- } \\
\text { based) }\end{array}$ & $\begin{array}{c}F \rightarrow W \\
\text { (time- } \\
\text { based) }\end{array}$ & $\begin{array}{l}\mathrm{F} \rightarrow W \\
\text { (strain- }^{\text {based) }} \\
\text { d }^{\text {b }}\end{array}$ & $\begin{array}{c}\text { Psychological } \\
\text { distress }\end{array}$ \\
\hline $\begin{array}{l}\text { Job } \\
\text { demands }\end{array}$ & $* * 0.19$ & $* * 0.14$ & $* * 0.23$ & $* 0.09$ & $* * 0.16$ & $* * 0.16$ \\
\hline $\begin{array}{l}\text { Decision } \\
\text { latitude }\end{array}$ & & $*_{-} 0.08$ & $*_{-} 0.07$ & -0.05 & $* *_{-} 0.13$ & $* *_{-} 0.14$ \\
\hline $\begin{array}{l}\mathrm{W} \rightarrow \mathrm{F} \\
(\text { time-based })^{\mathrm{a}}\end{array}$ & & & $* * 0.59$ & $* * 0.58$ & $* * 0.41$ & $* * 0.12$ \\
\hline $\begin{array}{l}\mathbf{W} \rightarrow \mathbf{F} \\
(\text { strain-based) }\end{array}$ & & & & $* * 0.40$ & $* * 0.47$ & $* * 0.19$ \\
\hline $\begin{array}{l}\mathrm{F} \rightarrow W \\
\text { (time-based) }^{c}\end{array}$ & & & & & $* * 0.56$ & $* * 0.14$ \\
\hline $\begin{array}{l}F \rightarrow W \\
(\text { strain-based) }\end{array}$ & & & & & & $* * 0.29$ \\
\hline $\begin{array}{l}\text { Psychological } \\
\text { distress }\end{array}$ & & & & & & \\
\hline
\end{tabular}

a Time-based work-to-family conflict

${ }^{\mathrm{b}}$ Strain-based work-to-family conflict

${ }^{c}$ Time-based family-to-work conflict

${ }^{\mathrm{d}}$ Strain-based family-to-work conflict

$* \mathrm{p} \leq 0.05 ; * * \mathrm{p} \leq 0.01$ 
Table 3: Ranges and Internal Reliability Estimates for Study Scales

\begin{tabular}{lcc}
\hline \multicolumn{1}{c}{ Variable } & Range & $\begin{array}{c}\text { Cronbach's } \\
\text { alpha }\end{array}$ \\
\hline Psychological demands & $10-40$ & 0.64 \\
Decision latitude & $9-36$ & 0.74 \\
Time-based work-to-family conflict & $3-15$ & 0.86 \\
Strain-based work-to-family conflict & $3-15$ & 0.84 \\
Time-based family-to-work conflict & $3-15$ & 0.84 \\
Strain-based family-to-work conflict & $3-15$ & 0.84 \\
Psychological distress & $0-24$ & 0.80 \\
\hline
\end{tabular}


Table 4: Demographic, Psychosocial, and Work-Family Conflict Characteristics, by Partner Status

\begin{tabular}{|c|c|c|}
\hline & $\begin{array}{c}\text { Partnered } \\
\text { Mothers } \\
(n=438)\end{array}$ & $\begin{array}{c}\text { Single } \\
\text { Mothers } \\
(\mathbf{n}=\mathbf{2 3 6})\end{array}$ \\
\hline & \multicolumn{2}{|c|}{$\%$} \\
\hline \multicolumn{3}{|l|}{ Educational attainment** } \\
\hline High school or less & 28.8 & 39.8 \\
\hline Some postsecondary & 29.0 & 29.2 \\
\hline College/university & 42.2 & 30.9 \\
\hline \multicolumn{3}{|c|}{ Child $\leq 5$ years of age living in household } \\
\hline No & 47.0 & 50.8 \\
\hline Yes & 53.0 & 49.2 \\
\hline \multicolumn{3}{|l|}{ Psychosocial work experience** } \\
\hline Low & 27.6 & 15.4 \\
\hline Passive & 24.4 & 22.4 \\
\hline Active & 29.9 & 35.5 \\
\hline \multirow[t]{2}{*}{ High strain } & 18.1 & 26.8 \\
\hline & \multicolumn{2}{|c|}{ Mean (SD) } \\
\hline Age** & $36.69(7.06)$ & $35.15(7.27)$ \\
\hline Number of children & $2.02(0.94)$ & $1.88(0.86)$ \\
\hline Weekly work hours* & $36.74(10.68)$ & $38.61(11.32)$ \\
\hline $\begin{array}{l}\text { Perceived income adequacy** } \\
\text { (scale range: } 1-5 \text { ) }\end{array}$ & $3.31(0.88)$ & $2.88(1.01)$ \\
\hline \multicolumn{3}{|l|}{ Psychosocial job quality } \\
\hline Decision latitude** & $27.07(4.77)$ & $25.69(4.82)$ \\
\hline Psychological demands & $24.39(4.19)$ & $25.03(4.57)$ \\
\hline \multicolumn{3}{|l|}{ Work-family conflict } \\
\hline Time-based Work-to-Family** & $7.00(3.08)$ & $8.11(3.67)$ \\
\hline Strain-Based Work-to-Family** & $6.84(2.84)$ & $7.49(2.88)$ \\
\hline Time-Based Family-to-Work & $6.05(2.62)$ & $6.43(3.04)$ \\
\hline Strain-Based Family-to-Work* & $5.70(2.51)$ & $6.12(2.50)$ \\
\hline Psychological distress* & $3.09(3.78)$ & $4.50(3.91)$ \\
\hline
\end{tabular}

${ }^{*} \mathrm{p} \leq 0.05 ; * * \mathrm{p} \leq 0.01$ 


\subsection{Correlates of Psychological Distress}

Multiple linear regression was used to examine whether single mothers' higher levels of psychological distress could be explained by differences between these two groups in their experience of work-family conflict and/or in the psychosocial quality of their work environment. To meet the normality assumptions of linear regression, the psychological distress variable and three of the work-family conflict variables (i.e., timebased family-to-work conflict, strain-based family-to-work conflict, and strain-based work-to-family conflict) were square root transformed to reduce the degree of positive skewness. Assessment of the variance inflation factors and tolerance levels indicated that multicollinearity was not an important concern in the analysis.

The models based on the incremental addition of variable-blocks showing the relationship of partner status, sociodemographic characteristics, psychosocial work quality, and work-family conflict to psychological distress are displayed in Table 5. Model 1 shows the crude relationship between partner status and psychological distress, indicating that single mothers have significantly higher levels of distress than partnered mothers. Results in subsequent models show this relationship diminished as key covariables were added. In Model 2, with the addition of sociodemographic variables, partner status was no longer statistically significantly associated with psychological distress. Women with some post-secondary education had significantly higher distress levels than college/university graduates. In addition, more children and greater perceived income adequacy was associated with lower distress levels. In Model 3, the psychosocial work quality measures were entered into the equation, resulting in the standardized beta coefficient for partner status further decreasing in strength. Although number of children 
was no longer associated with distress, having only some post-secondary training and lower perceived income adequacy remained statistically significant. In addition, women in active and high strain work environments had significantly higher levels of psychological distress than those in low-strain environments. When the work-family conflict variables were added in Model 4, the beta coefficient for partner status, though remaining statistically non-significant, became negative in value. In the final model, the following factors were associated with higher levels of psychological distress: having some post-secondary training (compared to university/college graduates), lower perceived income adequacy, high-strain psychosocial work environment (compared to low-strain) and higher levels of strain-based, family-to-work conflict. The final model accounted for $14 \%$ of the variation in psychological distress. 
Table 5: Summary of Hierarchical Linear Multiple Regression Predicting Psychological Distress $\dagger$

\section{Model $1 \quad$ Model $2 \quad$ Model $3 \quad$ Model 4}

Unpartnered $^{\text {a }}$

Age

Education $^{\mathrm{b}}$

Some post-secondary

High school or less

Number of children ${ }^{\mathrm{c}}$

Child $\leq 5$ years of age living in household $^{\mathrm{d}}$

Weekly work hours

Perceived income adequacy

Psychosocial work quality ${ }^{\mathrm{e}}$

Active

Passive

High strain
$* 0.08$

0.03

0.01

$-0.02$

$-0.05$

$-0.06$

$-0.06$

$\begin{array}{rrr}* 0.11 & * 0.10 & * 0.10 \\ 0.05 & 0.05 & 0.05\end{array}$

$*_{-0.09} \quad-0.07$

$-0.07$

0.01

0.01

0.03

$$
-0.02
$$

$-0.05$

$-0.07$

$* *-0.18 \quad * *-0.17 \quad * *-0.13$

$* 0.11$

0.09

$0.01 \quad 0.01$

**0.19 **0.13

Work-family conflict

Time-Based Work-to-Family

0.03

$-0.01$

Time-Based Family-to-Work

$* * 0.27$

Adjusted $\mathrm{R}^{2}$

0.00

0.05

0.08

0.14

F for change in $\mathrm{R}^{2}$

$* 3.73$

$* * 5.51$

**6.88

$* * 12.39$

$\dagger$ Note: standardized regression coefficients (beta) are reported; ${ }^{*} \mathrm{p} \leq 0.05 ;{ }^{* *} \mathrm{p} \leq 0.01$

${ }^{a}$ compared to partnered women; ${ }^{b}$ compared to university/college graduates; ${ }^{c}$ compared to one child; ${ }^{\mathrm{d}}$ compared to not being the mother of a young child; ${ }^{\mathrm{e}}$ compared to women in a low strain psychosocial work environment 


\section{CHAPTER 5}

\section{DISCUSSION}

Similar to the results of previous research with general population samples of single mothers (3-6), employed single mothers in this study reported significantly higher levels of psychological distress compared to their partnered counterparts. More importantly, however, after adjusting for differences between these two groups of women on sociodemographic characteristics, psychosocial work quality and work-family conflict, the absence of a partner was no longer statistically significantly associated with psychological distress.

\subsection{Links to the Literature}

Although comparisons of the health status of single and partnered mothers abound in the literature, much less research has focused on the well-being of single mothers who are employed. Of those few studies which have focused their attention specifically on the mental health of employed single mothers, several have found significantly lower rates of distress/depression for employed lone mothers as compared with those who are not employed. $(3,37)$ Other research, however, has failed to find any benefits of employment. For example, a Swedish study found significantly higher rates of 'less than good health' as well as limiting longstanding illness among employed lone mothers relative to employed partnered mothers.(63) In a longitudinal study of mothers moving in and out of employment in Ontario,(38) no significant reduction in psychological distress was observed among single mothers who made the transition from unemployment into paid work. Similarly, in another longitudinal study of inner city women living in the U.K., full-time employment was a significant risk factor for the development of depression 
among single mothers but not among partnered mothers.(22) Although the present study did not include unemployed women as a comparison group, our findings are consistent with research suggesting that employment status per se is not necessarily associated with enhanced psychological well-being for single mothers relative to partnered mothers.

While employment has been associated with positive consequences, such as increased financial independence and enhanced social support,(33) the benefits for single mothers may be more limited. An important expectation of employment is that it will result in enough income to cover the costs of raising a family. However, this relationship may not always hold true for single mothers who often have only one income to cover household expenses. That is, employment for single mothers does not necessarily translate into less financial hardship. $(64,65)$ For single mothers who must take lowpaying jobs with few benefits and little security, the financial incentive for employment may be counterbalanced by the costs of child-care, transportation, and other work-related expenses.(66) Canadian data suggest that although employment for single mothers has increased dramatically over the last few decades, employed single mothers are still much more likely than partnered mothers to have a low household income, particularly those who are younger with low educational attainment.(2) Similarly, in this study, although all of the single mothers were employed and reported working significantly more hours at their job each week than partnered mothers, they were less likely to have attained a college/university degree and to perceive that their income adequately covered their food, shelter and clothing expenses. Importantly, after adjusting for sociodemographic factors in the second step of the linear regression analysis, being a single mother was no longer statistically associated with higher psychological distress. These findings are somewhat 
consistent with previous research which has also highlighted socioeconomic disadvantage as partially responsible for the elevated psychological distress of single compared to partnered mothers. $(4,7,31)$ One notable difference was that in the majority of these studies, partner status was still found to have some bearing on the mental health of the participants, even after adjusting for employment and economic differences. However, unlike our study, these studies did not focus specifically on employed women.(4, 7,31$)$ Additional research is clearly needed to clarify the relationship between employment and mental health among single mothers who occupy a variety of socioeconomic positions.

Jobs vary not only in the economic returns provided but in psychosocial quality as well. According to Robert Karasek's job strain model of work stress, workers' job demands interact with their level of decision latitude to determine the psychosocial quality of their work. The most damaging reactions (e.g., fatigue, anxiety, depression) occur when the psychological demands of the job are high and the worker's ability to respond to more demands (i.e., decision latitude) is low. $(13,40,67)$ In the present study, employed single mothers reported a poorer psychosocial work environment than partnered mothers. That is, single mothers reported lower levels of workplace decision latitude and a greater proportion of single than partnered mothers were in the high strain quadrant of Karasek's job strain typology (i.e., high job demands and low job control). With the addition of the work quality variables into the regression equation, the relationship between partner status and psychological distress further decreased in magnitude. As previously mentioned, most research on employed single mothers has focused on employment status per se, rather than on the psychosocial quality of their paid work. At the same time, however, previous research suggests that employed single 
mothers, on average, are more likely to be working in positions of lower pay and status than partnered women. $(4,5,11)$ In turn, lower paying jobs tend to be associated with poorer psychosocial job characteristics. Karasek et al. noted that women who work in service occupations, such as waitresses, telephone operators and nurse's aides, frequently occupy this 'high strain' category.(40) In line with Karasek et al., a significantly greater proportion of single than partnered mothers in this study were found in the lower categories of educational attainment (i.e., high school or less and some postsecondary) and so, it would not come as a great surprise for them to occupy a greater presence in service or retail occupations where higher education is not required.

Lower-status jobs are typically less flexible and less accommodating when children are sick or new arrangements are required.(66) Employment also reduces the time one has to devote to parenting. Given these circumstances, it is certainly plausible that employment would increase family-related stress for single mothers. Although researchers have speculated that single parent status, due to the absence of a partner to provide emotional and functional support, is likely associated with greater difficulties in meeting the dual demands of home and work, $(3,26)$ the present study is among the first to systematically test this assumption. In this study, employed single mothers reported higher levels of three out of the four different forms of work-family conflict assessed: time-based work-to-family conflict, strain-based work-to-family conflict, and strainbased family-to-work conflict. Further, when the work-family conflict variables were added in Model 4, the beta coefficient for partner status, though remaining statistically non-significant, became negative in value, indicating a lower risk of distress for lone compared with partnered mothers. Several earlier studies attempting to address the 
differences between single and partnered mothers similarly reported that single mothers see themselves as having less support, less personal time, more stress, and greater difficulty balancing work and home life. $(51,54,68,69)$

It is important to note that not all previous research is consistent with the present study. That is, some other research suggests that single mothers do not experience more difficulty than partnered mothers in balancing home and work life. McManus and colleagues,(17) in a survey of women working in either hospitals or grocery stores, reported few differences between single and partnered mothers on measures of family demands, family satisfaction, work-to-family conflict or family-to-work conflict. The findings from a qualitative study of 50 mothers in the U.S who chose to be single parents suggested that many of the women coped well as employed single mothers, drawing extensively on the support of their community and extended family ties for assistance.(70) As concluded by one researcher, "the almost exclusive focus on the dysfunctions and distress of single-parent families does injustice to those solo parents who are relatively successful with regard to self-support and quality of life". (17; p. 1319) Finally, in a recent longitudinal study of single and married mothers living in London, Ontario,(27) although single mothers reported significantly higher levels of work-home strain during the first measurement period, this difference disappeared by the second measurement 18 months later. Also, in contrast to our findings, work-family conflict was not an important predictor of family structure differences in psychological distress. A major limitation of this study, however, was their measure of work-family conflict which was developed specifically for their study and assessed only a single dimension of workfamily conflict. The lack of significant findings may be due to their use of a study- 
specific scale which fails to clearly specify the direction and type of work-family conflict. That is, some aspects of work-family conflict may be more germane than others to understanding mental health inequalities between partnered and single employed mothers. The findings in this study suggest that strain-based, family-to-work conflict may be of particular importance in explaining differences in psychological distress for single and partnered mothers. That is, the psychological burden of bringing family concerns to the workplace may be more taxing on the well-being of working mothers than other types of work-family conflict, such as those involving time constraints or concerns which originate in the workplace. The vast majority of work-family conflict research has focused on the antecedents and consequences of stresses which originate in the workplace; $(18,20)$ more research is clearly needed exploring the ramifications of conflict which originates in the family domain for both partnered and single mothers.

\subsection{Study Limitations}

There were several important limitations with regard to study design. Due to the cross-sectional nature of the study, the extent to which higher levels of psychological distress might have contributed to participants becoming single mothers could not be determined. A longitudinal study examining the same variables would aid in deciphering the causal pathways between the statistically significant variables and their effect on psychological distress among employed single and partnered mothers.

In addition to design considerations, measurement limitations were also present. All variables were based on self-reported measures, thus reporting biases cannot be ruled out. The presence of psychological distress could influence the self-reporting of individuals. It is possible that people with higher levels of psychological distress are less 
likely to rate their work and family life favourably, rather than this working in the reverse causal direction. Perceived income adequacy was measured with a single item and it would have been preferable to have a more detailed measure of financial hardship and socioeconomic position. Also, access to potentially important information, such as custody arrangements and the duration of single parenthood, were not available in the present study. Among single mothers there is variability in terms of the other parent's level of involvement in their children's lives which would likely impact on the women's experience of single parenting. For instance, a single mother who shares custody of the children with her husband may experience less work-family conflict than mothers with sole custody. Shared custody may not only provide a single mother with instrumental and emotional assistance in child-rearing, but may also mean more free time to participate in stress reducing leisure activities, such as hobbies or socializing with friends. Also not addressed in the present study was the presence of other supportive people, such as grandparents, who may be available to assist working mothers in the daily demands of raising a family as a single parent. Regarding the duration of single parenthood, a recently divorced mother may experience a higher level of psychological distress than a woman who has been divorced for a longer period of time and has had the time needed to "regroup" - economically, psychologically and socially.

\subsection{Study Implications}

Understanding the causal mechanisms of greater psychological distress among employed single mothers compared with partnered mothers is important for informing policy development. While the cross-sectional design of the present study obviously limits the extent to which conclusions about causation can be made, these findings, in 
combination with previous research, provide some directions for policy development. Employment in and of itself is unlikely to be effective in enhancing the well-being of single mothers without an adequate household income, a positive psychosocial work environment, and the necessary supports to successfully balance the demands of work and family life. Single mothers in Canada have made considerable educational, employment, and financial gains over the last several decades(2) and some single mothers, like partnered mothers, may be thriving in their work, family and life roles.(17, 70) For a significant portion of single mothers in Canada, however, low educational attainment likely dooms them to low paying jobs with little chance of financial security, fulfilling employment, or access to work-family benefits. $(2,66)$

Full-time employment for single parents in Canada significantly lessens the likelihood of being in a low income situation.(2) For example, in 2000, 14\% of full-time employed single mothers had a low income, compared with $62 \%$ of those single mothers in other employment categories (including unemployed). However, for young lone mothers with low education, this was not the case.(2) That is, for 25-34 year old single mothers who did not finish high school but were working full-time in 2000, 37\% had a low income, up from $23 \%$ in 1980 . The importance of educational attainment as a pathway out of poverty for lone mothers was also highlighted in the results of a recent Canadian study with teenage mothers.(71) This study found, as have others, that having a baby in one's teens is associated with low educational attainment, which in turn leads to lower labour force participation and a higher incidence of low income. However, teenage mothers who were able to attain post-secondary education were actually more likely to be in full-year, full-time employment than mothers who first gave birth as an adult. 
Similarly, in the United States, Zhan and Pandey found that single mothers who had obtained post-secondary education (i.e., in particular a 4-year college degree) were nine times more likely to live above the federal poverty line, than those single mothers and fathers who had attained less than a high school diploma.(72) Various levels of government could provide programs or measures aimed at reducing the educational attainment inequities experienced by single mothers, such as reducing or waiving tuition fees and providing access and subsidies for quality childcare.

To combat some of the health inequities experienced by employed single mothers, a number of policies and programs within the workplace could be designed and implemented. For instance, occupational stress interventions could be implemented to address the psychosocial work environment, focusing on either the employee or the workplace. On an individual level, these interventions may include training sessions in coping strategies, progressive relaxation, or other stress management techniques, some of which have been proven to reduce symptoms of stress. $(73,74)$ However, it is important to note that unless the source of workplace stress is eliminated, the effectiveness of these techniques may decrease over time.(75) Practices that could reduce workplace stress may include increasing the employees' overall job control, skill use, and reducing work-role conflict, by encouraging employees to be active in decision making processes, broadening job activities, and identifying job roles and responsibilities respectively.(76, 77) Workplaces could promote educational opportunities focused on furthering knowledge and/or training to help address the economic challenges experienced by single mothers. 
In addition, policies that are supportive and responsive to family needs could be implemented to give workers more control and a sense of empowerment. Access to workplace supports $(51,78)$ such as paid sick leave and family leave, as well as health insurance and childcare subsidies, could aid in reducing the overall distress faced by single mothers. Flexible work schedules for single mothers would likely prove to be very beneficial in helping them balance their multiple roles. This could be offered formally (i.e., workplace-sponsored flextime)(79) or informally to alleviate some of the concerns of women who face periodic challenges to arriving at work in a timely manner, such as in cases where last-minute childcare arrangements must be made $(49,66)$.

\subsection{Conclusion}

While single employed mothers did experience higher levels of psychological distress than their partnered counterparts, differences in sociodemographic factors, psychosocial work quality, and work-family conflict were found to explain this relationship. Once these differences were controlled for statistically, the association between partner status and distress was removed. This suggests that being a single mother in and of itself need not result in poorer mental health. However, greater attention needs to be paid to the economic well-being and psychosocial work environment of single mothers, including policies to facilitate work-family balance. 


\section{REFERENCES}

1. Statistics Canada. Women in Canada. $5^{\text {th }}$ Edition. A gender-based statistical report. 2006; Catalogue no. 89-503-XIE.

2. Galarneau D. Education and income of lone parents, Perspectives in Labour and Income, 2005;6(12). Statistics Canada. Catalogue no. 75-001, Ottawa.

3. Baker D, North K. The ALSPAC Study Team. Does employment improve the health of lone mothers? Soc Sci Med. 1999;49:121-131.

4. Cairney J, Boyle M, Offord DR, Racine Y. Stress, social support and depression in single and married mothers. Soc Psychiatry Psychiatr Epidemiol. 2003;38:442-49.

5. Perez C, Beaudet MP. The health of lone mothers. Health Rep. 1999;11(2):21-32.

6. Benzeval M. The self-reported health status of lone parents. Soc Sci Med. 1998;46(10):1337-53.

7. Hope S, Power C, Rodgers. Does financial hardship account for elevated psychological distress in lone mothers? Soc Sci Med. 1999;49:1637-1649.

8. Mathers CD, Schofield DJ. The health consequences of unemployment: the evidence? Med J Australia. 1998;168:178-182.

9. Barnett, RC, Hyde, J. Women, men, work, and family: An expansionist theory. American Psychologist. 2001;56:781-796.

10. McMunn A, Bartley M, Hardy R, Kuh D. Life course social roles and women's health in mid-life: causation or selection? J Epidemiol Community Health. 2006;60:484489.

11. Lipman EL, Offord DR, Boyle MH. Single mothers in Ontario: sociodemographic, physical and mental health characteristics. CMAJ. 1997;156:639-645.

12. Karasek R, Theorell T. Healthy work: Stress, productivity and the reconstruction of working life. New York: Basic Books; 1990.

13. Cheng Y, Kawachi I, Coakley E, Schwartz J, Colditz G. Association between psychosocial work characteristics and health functioning in American women: prospective study. BMJ. 2000;320:1432-1436.

14. Stansfeld S, Bosma H, Hemingway H, Marmot M. Psychosocial work characteristics and social support as predictors of SF-36 health functioning: the Whitehall II study. Psychosomatic Medicine. 2001;60(3):247-255. 
15. Pikhart H, Bobak M, Pajak A, Malyutina S, Kubinova R, Topor R, et al. Psychosocial factors at work and depression in three countries of central and eastern Europe. Soc Sci Med. 2004;58:1475-1482.

16. Eagle B, Icenogle M, Maes J, Miles E. The importance of employee demographic profiles for understanding experiences of work-family interrole conflicts. J Soc Psychol. 1998;138:690-709.

17. McManus K, Korabik K, Rosin H, Kelloway E. Employed mothers and the workfamily interface: does family structure matter? Human Relations. 2002;55(11):12951324.

18. Allen T, Herst D, Bruck C, Sutton M. Consequences associated with work-to-family conflict: A review and agenda for future research. J Occup Health Psychol. 2000;(2): 278-308.

19. Frone M. Work-to-family conflict and employee psychiatric disorders: The National Comorbidity Survey. J Appl Psychol. 2000;85:888-895.

20. Casper WJ, Eby LT, Bordeaux C, Lockwood A, Lambert D. A review of research methods in IO/OB work-family research. J Appl Psychol. 2007;92(1):28-43.

21. Carlson D, Kacmar K, Williams L. Construction and initial validation of multidimensional measure of work-family conflict. J Vocat Behav. 2000;56:249-276.

22. Brown GW, Moran PM. Single mothers, poverty and depression. Psychol Med. 1997;27:21-33.

23. Crosier T, Butterworth P, Rodgers B. Mental health problems among single and partnered mothers. Soc Psychiatr Psychiatr Epidemiol. 2007;42:78-92.

24. DeKlyen M, Brooks-Gunn J, McLanahan S, Knab J. The mental health of married, cohabiting, and non-co resident parents with infants. AJPH. 2006;96:1836-1841.

25. Butterworth $P$. The prevalence of psychiatric disorders among lone mothers: association with physical and sexual violence. Br J Psychiat. 2004;184:21-27.

26. Weitoft GR, Haglund B, Hjern A, Rosén M. Mortality severe morbidity and injury among long-term lone mothers in Sweden. Int J Epidemiol. 2002;31:573-80.

27. Avison W, Ali J, Walters D. Family structure, stress, and psychological distress: A demonstration of the impact of differential exposure. J Health Soc Behav. 2007;48 (September):301-317.

28. Avison W, Davies L. Family structure, gender, and health in the context of the life course. J Gerontol. 2005;60B:113-116. 
29. Wang J. The difference between single and married mothers in the 12-month prevalence of major depressive syndrome, associated factors and mental health service utilization. Soc Psychiatry Psychiatr Epidemiol. 2004;39:26-32.

30. Lipman E, McMillan H, Boyle M. Childhood abuse and psychiatric disorders among single and married mothers. Am J Psychiatr. 2001;158:73-77.

31. Lahelma E, Arber A, Kivel K, Roos E. Multiple roles and health among British and Finnish women: The influence of socio-economic circumstances. Soc Sci Med. 2002;54:727-740.

32. Goode WJ. A theory of role strain. Am Socio Rev. 1960;25:483-496.

33. Barnett RC, Hyde J. Women, men, work, and family: An expansionist theory. Am Psychol. 2001;56:781-796.

34. Janzen B, Muhajarine N. Social role occupancy, gender, income adequacy, life stage and health: a longitudinal study of employed Canadian men and women. Soc Sci Med. 2003;57:1491-1503.

35. McMunn A, Bartley M, Hardy R, Kuh D. Life course social roles and women's health in mid-life: causation or selection? J Epidemiol Community Health. 2006;60:484 489 .

36. Whitehead M, Burström B, Diderichsen F. Social policies and the pathways to inequalities in health: a comparative analysis of lone mothers in Britain and Sweden. Soc Sci Med. 2000;50:255-70.

37. Maclean H, Glynn K. and Ansara D. Multiple roles and women's mental health in Canada. Women's Health Surveillance Report. CIHI: Ottawa; 2003.

38. Ali J, Avison WR. Employment transitions and psychological distress: the contrasting experiences of single and married mothers. J Health Soc Behav. 1997;38(4):345-62.

39. Arber S. Class, paid employment and family roles: Making sense of structural disadvantage, gender and health status. Soc Sci Med. 1991;32(4):425-436.

40. Karasek R, Brisson C, Kawakami N, Houtman I, Bongers P, Amick B. The Job Content Questionnaire: An instrument for internationally comparative assessments of psychosocial job characteristics. J Occup Health Psychol. 1998;3: 322-355.

41. Emslie C, Hunt K, Macintyre S. Gender, work-home conflict, and morbidity amongst white-collar bank employees in the United Kingdom. Inter J Behavioral Med. 2004;11(3):127-134. 
42. Griffin J, Fuhrer R, Stansfeld S, Marmot M. The importance of low control at work and home on depression and anxiety: do these effects vary by gender and social class? Soc Sci Med. 2002;54:783-798.

43. Lennon MC, Rosenfield S. Women and mental health: The interaction of job and family conditions. J Health Soc Behav. 1992;33(4):316-327.

44. Greenhaus J, Beutell N. Sources of conflict between work and family roles. Acad Manag Rev. 1985;10(1):76-88.

45. Grzywacz J, Bass B. Work, family, and mental health: Testing different models of work-family fit. J Marriage Fam. 2003;65(1):248-261.

46. Allen TD, Herst DE, Bruck CS, Sutton M. Consequences associated with work-tofamily conflict: A review and agenda for future research. J Occup Health Psychol. 2000;5:278-308.

47. Eby LT, Casper J, Lockwood A, Bordeaux C, Brinley A. (2005). Work and family research in IO/OB: Content analysis and review of the literature (1980-2002). J Vocat Behav. 2005;66(1):124-197.

48. Haas L. Families and work. In Sussman M, Steinmetz SK, Peterson GW, editors. Handbook of marriage and the family. New York, Plenum: $2^{\text {nd }}$ ed. 1999. p. 571-612.

49. Lambert SJ. Lower-wage workers and the new realities of work and family. Ann Am Acad Polit Soc Sci. 1999;562:174-190.

50. Marks S, Leslie L. Handbook of family diversity: Toward a richer approach to multiple roles. New York: Oxford University Press; 2000.

51. Casey J, Pitt-Catsouphes M. Employed single mothers: Balancing job and homelife. Employee Assistance Quarterly. 1994;9:37-53.

52. Duxbury L, Higgins C, Lee C. Work-family conflict: A comparison by gender, family type, and perceived control. J Fam Issues. 1994;15:449-66.

53. Greenberger E, Goldberg WA, Hamill S, O’Neil R, Payne CK. Contributions of a supportive work environment to parents' well-being and orientation to work. Am J Community Psychol. 1989;17:755-83.

54. Vinet M.J, The work and family contexts of employed single mothers: An exploratory model [unpublished doctoral dissertation]. Seattle (WA): University of Washington; 1988.

55. Ciabattari T. Single mothers, social capital, and work-family conflict. J Fam Issues. 2007;28:34-60. 
56. Lapierre L, Allen T. Work-supportive family, family-supportive supervision, use of organizational benefits, and problem-focused coping: Implications for work-family conflict and employee well-being. J Occup Health Psychol. 2006;11:169-181.

57. Kessler R, Barker P, Colpe J, Epstein J, Gfroerer J, Hiripi E, et al. Screening for serious mental illness in the general population. ArchGen Psychiatr. 2003;60:184189.

58. Kessler R, Andrews G, Colpe L, Hiripi E, Mroczek D, Normand S, et al. Short screening scales to monitor population prevalences and trends in nonspecific distress. Psychol Med. 2002;32:959-976.

59. Furukawa TA, Andrews G, Slade T, Kessler RC. The performance of the K6 and K10 screening scales for psychological distress in the Australian National Survey of Mental Health and Well-Being. Psychol Med. In press.

60. Weissman M, Leaf P, Bruce JL. Single parent women. Soc Psychiatr. 1987;22:29-36.

61. Tabachnik B, Fidell L. Using multivariate statistics. $5^{\text {th }}$ ed. MA: Allyn \& Bacon; 2006.

62. Nunnally JC. Psychometric theory. $2^{\text {nd }}$ ed. New York: McGraw-Hill; 1978.

63. Burström B, Diderichsen F, Shouls S, Whitehead M. Lone mothers in Sweden: trends in health and socio-economic circumstances, 1979-1995. J Epidemiol Community Health. 1999;53:750-56.

64. Morissette R, Picot G. Low-paid work and economically vulnerable families over the last two decade, Analytical Studies Branch research paper series, 2005. Statistics Canada. Catalogue no. 11F00019-MIE no. 232, Ottawa.

65. Chung, Lucy. Low-paid workers: How many live in low-income families? Perspectives in Labour and Income, 2004. Statistics Canada. Catalogue no. 75-001XIE.

66. Mason R. Listening to lone mothers: Paid work, family life and childcare in Canada. Journal of Children and Poverty. 2003;9(1):41-54.

67. Vermeulen M, Mustard C. Gender differences in job strain, social support at work, and psychological distress. J Occup Health Psychol. 2000;5(4):428-40

68. Kelly RF, Voydanoff P. Work/family role strain among employed parents. Family Relations. 1985;34:367-374.

69. Burris BH. Employed mothers: The impact of class and marital status on the prioritizing of family and work. Social Science Quarterly. 1991;72:50-66. 
70. Hertz R, Ferguson F. Only one pair of hands: ways that single mothers stretch work and family resources. Community Work Fam. 1998;1(1):13-37.

71. Luong M. Life after teenage motherhood. Perspectives in Labour and Income, 2008; May. Statistics Canada. Catalogue no. 75-001-XIE

72. Zhan M, Pandey S. Postsecondary education and economic well-being of single mothers and single fathers. J Marriage Fam. 2000;66(3):661-673.

73. Koeski G, Kirk S, Koeske R. Coping with job stress: which strategies work best? J Occup Organizational Psychol. 1993;66:319-335.

74. Martin E. Designing stress training. In: Quick J, Murphy L, editors. Stress and wellbeing at work. Washington, DC: American Psychological Association; 1992.

75. Murphy LR. A review of organizational stress management research: Methodological considerations. In: Ivancevich JM, Ganster DC, editors. Job stress: from theory to suggestion. New York, NY: Haworth Press; 1987:215-227.

76. Lowe GS, Schellenberg G, Shannon HS. Correlates of employees' perceptions of a healthy work environment. Am J Health Promot. 2003;17(6):390-9.

77. Nielsen ML, Rugulies R, Christensen KB, Smith-hansen L, Bjorner JB, Kristensen TS. Impact of the psychosocial work environment on registered absence from work: A two-year longitudinal study using the IPAW cohort. Work \& Stress. 2004;18(4):323-335.

78. Deitch CH, Huffman ML. Family-responsive benefits and the two- tiered labor market. In: Hertz R, Marshall NL, editors. Working Families: The transformation of the American Home. Berkeley: University of California Press; 2001. p. 103-130.

79. Glass JL, Estes SB. The family responsive workplace. Annu Rev Sociol. 1997;23:289-313. 


\section{APPEndiX A:}

\section{VARIABLES USED IN THE ANALYSIS}

1. Partner Status

$\square$ Married

Living with a partner

$\square$ Widowed

$\square$ Separated

$\square$ Divorced

$\square$ Single

2. Age

How old are you?

3. Number of children

How many children do you have?

4. Presence of a child $<5$ years of age

Do any of your children less than 5 years of age live within your household?

$\square$ Yes

$\square$ No

5. Weekly work hours

Approximately how many hours a week do you usually work at this job? If you usually work extra hours (paid or unpaid), please include these hours. hours

6. Perceived income adequacy

\begin{tabular}{|l|ccc|}
\hline $\begin{array}{l}\text { We have enough money to cover } \\
\text { basic needs for food, housing and } \\
\text { clothing. }\end{array}$ & 1 & 2 & 4 \\
& Strongly Disagree & Strongly Agree \\
\hline
\end{tabular}

7. Education

$\square$ Less than high school

Graduated from high school, but didn't go to a postsecondary institution

Some postsecondary training, but didn't graduate

$\square$ Graduated from a college

$\square$ Graduated from a university 
8. Psychological Distress

\begin{tabular}{|l|c|c|c|c|c|}
\hline $\begin{array}{l}\text { During the past month, about how } \\
\text { often did you feel... }\end{array}$ & $\begin{array}{c}\text { None } \\
\text { of the } \\
\text { time }\end{array}$ & $\begin{array}{c}\text { A } \\
\text { little } \\
\text { of the } \\
\text { time }\end{array}$ & $\begin{array}{c}\text { Some } \\
\text { of the } \\
\text { time }\end{array}$ & $\begin{array}{c}\text { Most } \\
\text { of the } \\
\text { time }\end{array}$ & $\begin{array}{c}\text { All } \\
\text { of the } \\
\text { time }\end{array}$ \\
\hline $\begin{array}{l}\text { so depressed that nothing could cheer you } \\
\text { up? }\end{array}$ & 0 & 1 & 2 & 3 & 4 \\
\hline hopeless? & 0 & 1 & 2 & 3 & 4 \\
\hline restless or fidgety? & 0 & 1 & 2 & 3 & 4 \\
\hline that everything was an effort? & 0 & 1 & 2 & 3 & 4 \\
\hline worthless? & 0 & 1 & 2 & 3 & 4 \\
\hline nervous? & 0 & 1 & 2 & 3 & 4 \\
\hline
\end{tabular}

9. Work-Family Conflict

Strongly Disagree

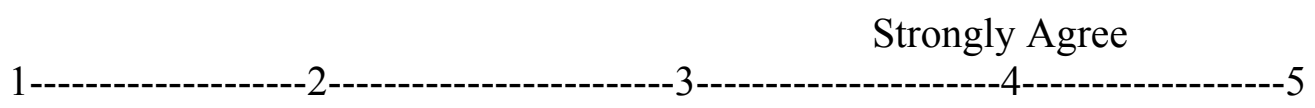

\begin{tabular}{|c|c|c|c|c|c|}
\hline \multicolumn{6}{|l|}{ Time based work-to-family conflict } \\
\hline $\begin{array}{l}\text { My work keeps me from my family activities more than I } \\
\text { would like }\end{array}$ & 1 & 2 & 3 & 4 & 5 \\
\hline $\begin{array}{l}\text { The time I must devote to my job keeps me from participating } \\
\text { equally in household responsibilities and activities }\end{array}$ & 1 & 2 & 3 & 4 & 5 \\
\hline $\begin{array}{l}\text { I have to miss family activities due to the amount of time I } \\
\text { must spend on work responsibilities }\end{array}$ & 1 & 2 & 3 & 4 & 5 \\
\hline \multicolumn{6}{|l|}{ Time based family-to-work conflict } \\
\hline $\begin{array}{l}\text { The time I spend on family responsibilities often interferes } \\
\text { with my work responsibilities }\end{array}$ & 1 & 2 & 3 & 4 & 5 \\
\hline $\begin{array}{l}\text { The time I spend with my family often causes me not to spend } \\
\text { time in activities at work that could be helpful to my career }\end{array}$ & 1 & 2 & 3 & 4 & 5 \\
\hline $\begin{array}{l}\text { I have to miss work activities due to the amount of time I } \\
\text { must spend on family responsibilities }\end{array}$ & 1 & 2 & 3 & 4 & 5 \\
\hline
\end{tabular}




\section{Strain-based work-to-family conflict}

When I get home from work I am often too frazzled to participate in family activities/responsibilities

I am often so emotionally drained when I get home from work that it prevents me from contributing to my family Due to all the pressures at work, sometimes when I come home I am too stressed to do the things I enjoy

\section{Strain based family-to-work conflict}

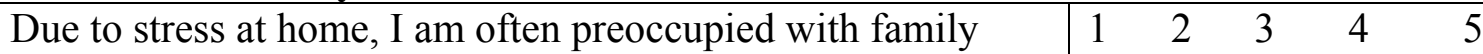
matter at work

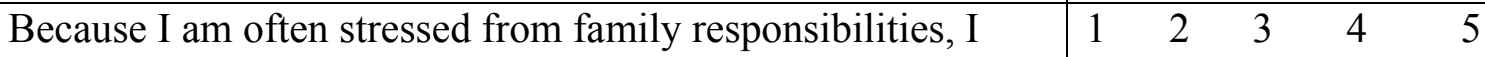
have a hard time concentrating on my work

Tension and anxiety from my family life often weakens my ability to do my job

\section{Job Content Questionnaire}

Strongly Disagre

Strongly Agree

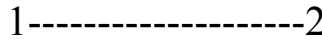

$-3$

\begin{tabular}{|c|c|c|c|c|}
\hline \multicolumn{5}{|l|}{ Psychological demands } \\
\hline My job requires working very fast. & 1 & 2 & 3 & 4 \\
\hline My job requires working very hard. & 1 & 2 & 3 & 4 \\
\hline I am not asked to do too much work. & 1 & 2 & 3 & 4 \\
\hline I have enough time to get the job done. & 1 & 2 & 3 & 4 \\
\hline The demands that other people make of me often conflict. & 1 & 2 & 3 & 4 \\
\hline My job requires long periods of intense concentration on the task. & 1 & 2 & 3 & 4 \\
\hline $\begin{array}{l}\text { My tasks are often interrupted before I can finish them so that I } \\
\text { have to go back to them later. }\end{array}$ & 1 & 2 & 3 & 4 \\
\hline My job is very hectic. & 1 & 2 & 3 & 4 \\
\hline $\begin{array}{l}\text { Waiting on work from other people or departments often slows me } \\
\text { down on my job. }\end{array}$ & 1 & 2 & 3 & 4 \\
\hline People I work with are competent in doing their jobs. & 1 & 2 & 3 & 4 \\
\hline
\end{tabular}




\begin{tabular}{|c|c|c|c|c|}
\hline \multicolumn{5}{|l|}{ Decision latitude } \\
\hline People I work with take a personal interest in me. & 1 & 2 & 3 & 4 \\
\hline People I work with are friendly. & 1 & 2 & 3 & 4 \\
\hline People I work with are helpful in getting the job done. & 1 & 2 & 3 & 4 \\
\hline My job requires that I learn new things. & 1 & 2 & 3 & 4 \\
\hline My job involves a lot of repetitive work. & 1 & 2 & 3 & 4 \\
\hline My job requires me to be creative. & 1 & 2 & 3 & 4 \\
\hline My job requires a high level of skill. & 1 & 2 & 3 & 4 \\
\hline I get to do a variety of different things on my job. & 1 & 2 & 3 & 4 \\
\hline I have an opportunity to develop my own special abilities. & 1 & 2 & 3 & 4 \\
\hline My job allows me to make a lot of decisions on my own. & 1 & 2 & 3 & 4 \\
\hline On my job, I have very little freedom to decide how I do my work. & 1 & 2 & 3 & 4 \\
\hline I have a lot of say about what happens on my job. & 1 & 2 & 3 & 4 \\
\hline
\end{tabular}




\section{APPENDIX B:}

\section{ETHICS APPROVAL}

To: $\quad$ Bonnie Janzen (Ewelina Dziak)

Date: January 8, 2008

Re: "Gender, Work, Family and Health" (Beh 04-64)

The study entitled, "Gender, Work, Family and Health" is exempt from the Research Ethics Board review process. This decision is based on the information provided in your letter to the Ethics Office on December 21, 2007.

Article 3.3 of the Tri-Council Policy Statement: Ethical Conduct for Research Involving Humans (1998) specifies that REB review and approval is not required to conduct a secondary analysis of data that cannot be linked to individuals, and for which there is no possibility that individuals can be identified in any published reports.

It should be noted that though your project is exempt of ethics review, your project should be conducted in an ethical manner (i.e. in accordance with the information that you submitted). It should also be noted that any deviation from the original methodology and/or research question should be brought to the attention of the Behavioural Research Ethics Board for further review.

Sincerely,

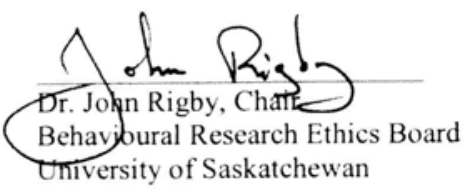

